\title{
European Journal of
}

\section{Health Sciences}

(EJHS)

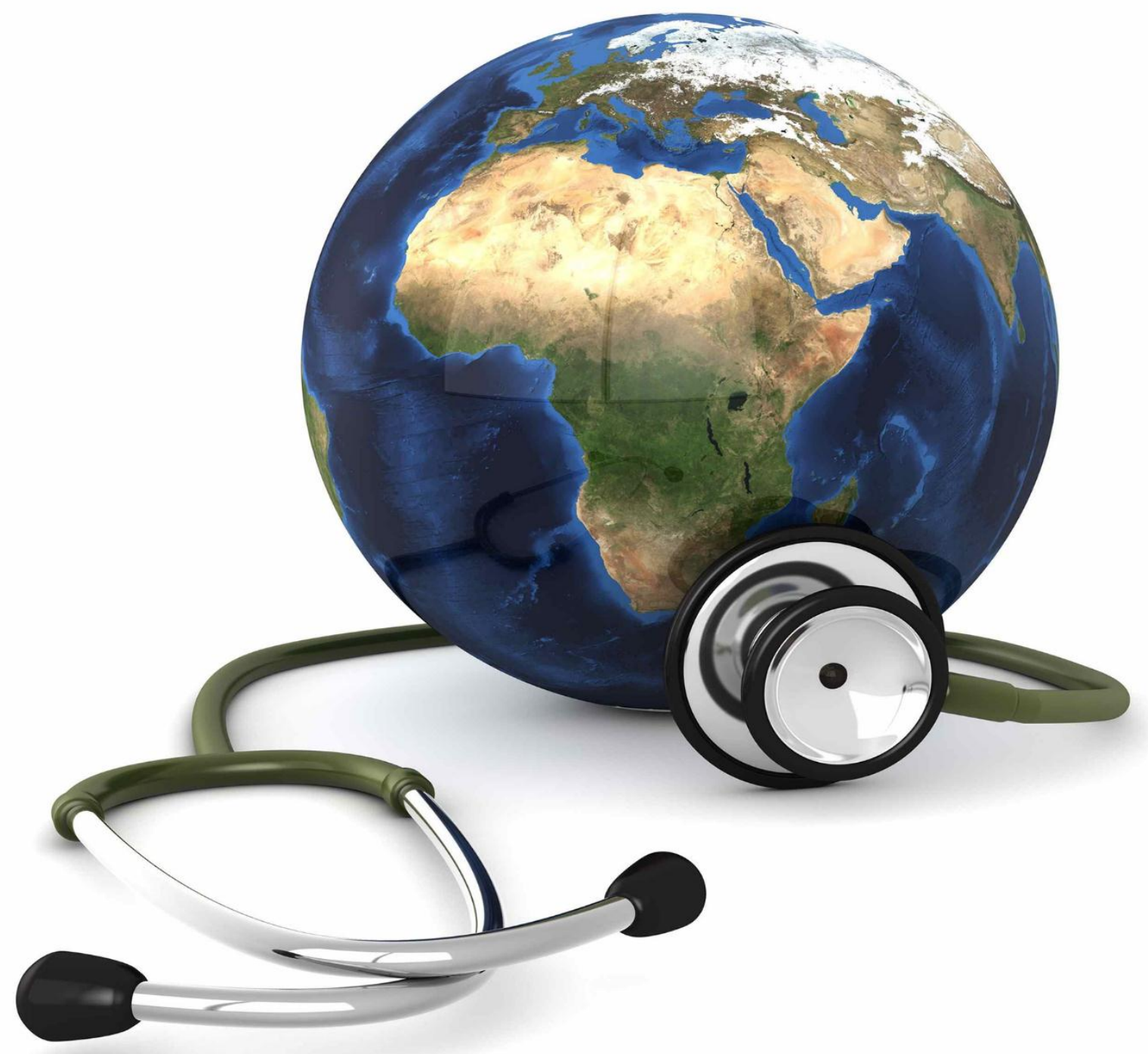

MICROBIAL DIVERSITY AND ANTIBIOTIC

RESISTANCE OF BACTERIA ON WASHROOM

FOMITES IN A PUBLIC UNIVERSITY

Reuben Essel Arhin

Henry Kwadwo Hackman (PhD)

Barry Kojo Whyte

Alhassan Sa-eed

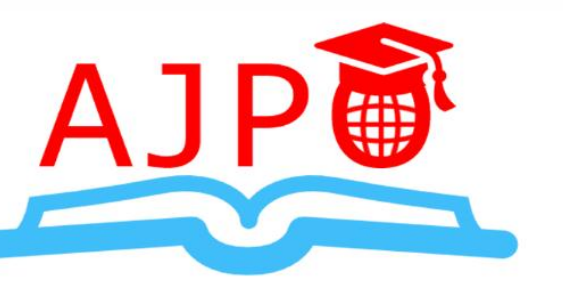




\title{
MICROBIAL DIVERSITY AND ANTIBIOTIC RESISTANCE OF BACTERIA ON WASHROOM FOMITES IN A PUBLIC UNIVERSITY
}

\author{
${ }^{* 1}$ Reuben Essel Arhin \\ Lecturer, Faculty of Applied Sciences \\ Accra Technical University \\ *Author's E-mail: rearhin@atu.edu.gh \\ ${ }^{2}$ Henry Kwadwo Hackman (PhD) \\ Senior Lecturer, Faculty of Applied Sciences \\ Accra Technical University \\ ${ }^{3}$ Barry Kojo Whyte \\ Lecturer, Faculty of Applied Sciences \\ Accra Technical University \\ ${ }^{4}$ Alhassan Sa-eed \\ Principal Laboratory Technologist, Faculty of Applied Sciences \\ Accra Technical University
}

\begin{abstract}
Purpose: To determine the diversity and distribution of bacteria contaminants on washroom fomites in a public university and their resistance to common antibiotics.

Methodology: A sanitation audit was conducted on 21 selected washrooms on seven different blocks in a university. Swabs were collected from 68 washroom fomites for bacterial isolation and biochemical identification. Antimicrobial susceptibility testing was performed for 22 Gram positive and 41 Gram negative bacteria species.

Findings: Of 21 washrooms none had toiletries, $71 \%$ did not have flowing water and $90 \%$ were in the category of generally unclean. Of 169 bacteria isolated Staphylococcus aureus and Escherichia coli were the predominant species. Of 68 fomites all had bacterial contaminants with $83.8 \%$ having 2 to 3 co-occurring species. Gram positive bacteria isolated were resistant to augmentin (100\%), meropenem (94\%), penicillin (91\%), cefuroxime $(86 \%)$, vancomycin $(86 \%)$, erythromycin (67\%), cloxacillin (64\%), tetracyclin (64\%), ciprofloxacin (59\%), cotrimoxazole $(59 \%)$, ampicillin $(50 \%)$ and gentamicin $(36 \%)$. Gram negative bacteria isolated were resistant to meropenem $(97 \%)$, ceftriaxone $(95 \%)$, ampicillin $(93 \%)$, cefuroxime $(91 \%)$, cefotaxime $(84 \%)$, vancomycin $(82 \%)$, tetracyclin $(80 \%)$, cotrimoxazole $(78 \%)$, chloramphenicol $(50 \%)$, ciprofloxacin $(71 \%)$, amikacin $(40 \%)$ and gentamicin $(24 \%)$.

Unique contribution to theory, practice and policy: Previous studies on bacteria on fomites in Ghana have focused on healthcare settings. This study focused on a university campus which is a non-healthcare setting with a high human presence and pressure on existing washroom facilities leading to contamination. The diversity of bacteria on the fomites are representative of clinically significant antibiotic resistant human enteric and skin flora carried by a seemingly healthy population and provide an indication of the potential antibiotic resistance burden in the user community.
\end{abstract}

Key Words: Diversity, antibiotics, fomites, contamination, flora 


\section{INTRODUCTION}

\subsection{Background of the Study}

The surroundings play a critical role in times of disease outbreaks. Public washrooms in university campuses are one of the places frequented by both residents and non-resident students who spend their day on campus to study or attend lectures. These washrooms present fomites for transmission of infections to hundreds of students who use these facilities on a daily basis. Fomites are inanimate objects which act as carriers of infectious diseases (Julian, 2010). In the control of infectious diseases a major means of transmission which many tend to pay less attention to is via fomites. These act as intermediate surfaces for indirect contact transmission of pathogens from one person to the other (Julian, 2010). Contamination of fomites occur via bodily fluids and skin of individual users who are carriers of a diversity of microorganisms and have different hygienic practices (Ogba \& Obio, 2018).

The warm and humid environment in washrooms (Suen et al.,2019) coupled with poor management, irregular flow of water for flushing and washing, unavailability of soap and tissue for sanitizing the hands are all factors which contribute to the spread of infectious diseases via these fomites. Damp hands are critical in transferring pathogens from contaminated fomites to other fomites (Margas, Maguire, Berlan, \& Welander, 2013) and may contribute to transfer of a diversity of human pathogens, some of which can survive for weeks or months on fomites (Suen et al., 2019).

In the advent of antibiotic resistance (World Health Organization (WHO), 2017) some of these pathogens contracted via contact with fomites may increase the cost of treatment, prolong morbidity and increase mortality. Washroom fomites on campuses may be a hub for spreading antibiotic resistant pathogens to the community making the campus a potential epicenter for disease outbreaks. Knowledge of the microbial diversity and resistance patterns of the bacterial contaminants may give information on the possibility of acquiring infections which are potentially difficult to treat and thus impact on the management of the washrooms and hygienic practices of the users of these facilities on campuses (Shanks \& Peteroy-Kelly, 2009).

\subsection{Problem Statement}

Bacteria are diverse in nature with some being human pathogens and having clinical significance. These are widespread and can be found on fomites. Fomites in places such as university campus washrooms are exposed to numerous human contacts on a daily basis and will harbor representative flora of the enteric parts and skin of the user community. Therefore washroom fomites are a means of indirect transmission of pathogenic bacteria through contact, especially in cases of poor management of such places. It is important to know the diversity and antibiotic resistance of representative flora on washroom fomites because these will provide supporting data for proper management and treatment in the event of infectious disease outbreaks.

\subsection{Research Objective}

The purpose of this study was to determine the diversity and distribution of bacteria contaminants on washroom fomites in a public university and their resistance to common antibiotics. 


\section{MATERIALS AND METHOD}

\subsection{Sample Collection}

A cross-sectional study design was employed. Observational data on sanitary conditions as well as swab samples for microbiological analysis were collected from selected washrooms. Samples were collected from 2 hostels and 5 lecture blocks in Accra Technical University from March to April, 2019. The university is located in the Central Business District of Accra, Ghana and occupies about 22.6 acres of land. The University has a student population of over 15,000 and seven storey blocks, two for resident students and five for lectures, laboratories and workshops. There is a moderate to heavy human traffic and a lot of pressure on the washroom facilities on a daily basis when the semester is in session.

One washroom on each floor was selected for sampling. Where both male and female washrooms where present on the same floor of a block these were included in the sampling. The inside door handle, first sink and first water closet cubicle upon entering each washroom were targeted for sampling. Each coded sterile cotton swab was moistened in physiological saline prior to swabbing of the selected fomite. Fomites were swabbed once by rolling the circumference of the cottonbudded end of a swab at $360^{\circ}$ over the surface. These were locked back into their coded cases and taken within 20 minutes to the Microbiology Laboratory of the Department of Science Laboratory Technology for processing. Each swab was cut into a labeled universal bottle containing $20 \mathrm{ml}$ of sterile peptone water and incubated for $18-24$ hours at $35-37^{\circ} \mathrm{C}$ to obtain a broth culture.

\subsection{Observational Data}

A structured questionnaire filled by trained sample collectors was used to obtain data on the sanitary conditions of 21 selected washrooms. The scores considered were availability of soap for hand washing, availability of flowing water through taps, provision of paper towels for hand cleaning and general cleanliness. A washroom was categorized as generally clean if the facility was tidy, had no visible dust and the floors were dry. Those that were not were categorized as generally unclean.

\subsection{Isolation and Identification of Bacteria}

After incubation, the content of each broth culture was inoculated onto labelled plates of Nutrient Agar (Biomark), MacConkey Agar (Biomark) and Mannitol Salt Agar (Oxoid). The plates were inverted and incubated aerobically at $35^{\circ}-37^{\circ} \mathrm{C}$ for $18-24$ hours. Preliminary identification of isolates was based on colony morphology on MacConkey Agar for Enterobacteriaceae and Mannitol Salt Agar for staphylococci. Gram staining and catalase test were performed on isolates. Gram negative catalase positive bacteria isolates were further identified by triple sugar iron, citrate, indole and urea test. Oxidase test was performed for Gram negative catalase negative bacteria.

\subsection{Antimicrobial Susceptibility Testing}

The disk diffusion method was employed in the determination of the antimicrobial susceptibility of selected clinically significant isolates using multidisc (Biomark Laboratories). Test for Gram positive bacteria included penicillin $(1.5 \mu \mathrm{g})$, ampicillin $(10 \mu \mathrm{g})$, cloxacillin $(5 \mu \mathrm{g})$, erythromycin $(5 \mu \mathrm{g})$, tetracycline $(30 \mu \mathrm{g})$, vancomycin $(30 \mu \mathrm{g})$, cotrimoxazole $(25 \mu \mathrm{g})$, cefuroxime $(10 \mu \mathrm{g})$, gentamicin $(10 \mu \mathrm{g})$, ciprofloxacin $(5 \mu \mathrm{g})$, augmentin $(30 \mu \mathrm{g})$ and meropenem $(10 \mu \mathrm{g})$. Test for Gram 
negative bacteria included ampicillin $(10 \mu \mathrm{g})$, tetracycline $(10 \mu \mathrm{g})$, cotrimoxazole $(10 \mu \mathrm{g})$, gentamicin $(10 \mu \mathrm{g})$, cefuroxime $(30 \mu \mathrm{g})$, vancomycin $(30 \mu \mathrm{g})$, chloramphenicol $(10 \mu \mathrm{g})$, ceftriaxone $(30 \mu \mathrm{g})$, cefotaxime $(30 \mu \mathrm{g})$, ciprofloxacin $(5 \mu \mathrm{g})$, amikacin $(30 \mu \mathrm{g})$ and meropenem $(10 \mu \mathrm{g})$. Controls were set using Escherichia coli ATCC 25922 and Staphylococcus aureus ATCC 29213. Zone sizes were interpreted according to CLSI 2018 guidelines on antimicrobial susceptibility testing.

\subsection{Data Analysis}

Data was captured on Microsoft Excel and imported to IBM SPSS Statistics 20 for descriptive analysis using cross tabulations. Nonparametric one sample Chi-square test was used to determine whether the categories under types of fomites, categories under species of bacteria and categories under antimicrobial susceptibility test occur with equal probability. Chi-square test was used to determine whether the type of fomite and the predominant bacteria isolated were independent. $\mathrm{P}$ values $<0.05$ were considered as statistically significant leading to rejection of the null hypothesis.

\section{RESULTS}

\subsection{Sanitation Audit of Washrooms}

Frequency distribution of sanitation audit results on the washrooms $(n=21)$.

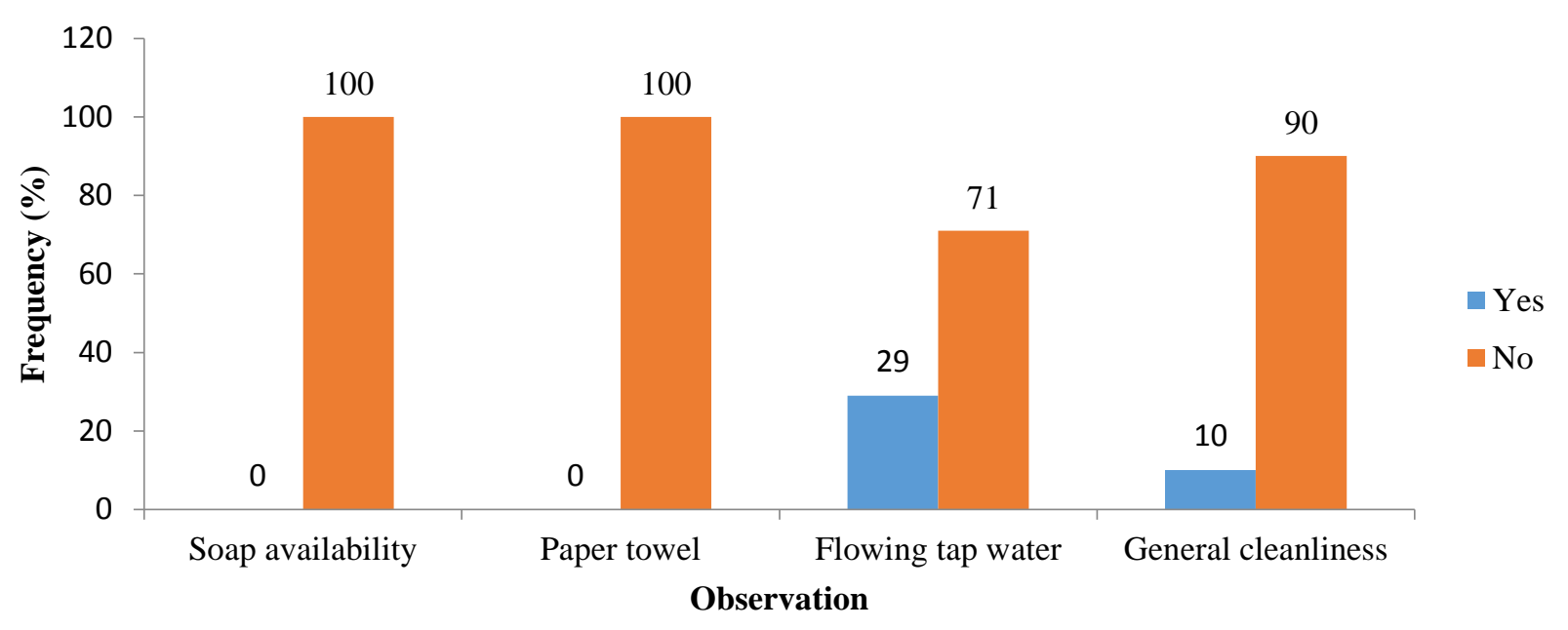

Figure 1: Sanitation Audit of Washrooms

As shown in Figure 1, none of the washrooms had soap or paper towels for users to sanitize their hands after visiting the facility. Of 21 washrooms $71 \%$ did not have water flowing through the taps and $90 \%$ were categorized as generally unclean.

\subsection{Microbial Diversity}

The diversity of bacteria on the washroom fomites are presented in Table 1. 
European Journal of Health Sciences

ISSN 2520-4645 (online)

Vol.5, Issue1, pp 1- 11, 2020

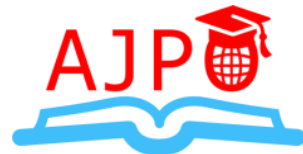

www.ajpojournals.org

\section{Table 1: Microbial Diversity}

The species and occurrence of bacteria $(n=169)$ on different washroom fomites

\begin{tabular}{|c|c|c|c|c|c|}
\hline \multirow[t]{2}{*}{ Species of Bacteria } & \multicolumn{5}{|c|}{ Fomite } \\
\hline & $\begin{array}{c}\text { Toilet } \\
\text { seat }\end{array}$ & $\begin{array}{l}\text { Flush } \\
\text { lever }\end{array}$ & $\begin{array}{c}\text { Tap } \\
\text { handle }\end{array}$ & $\begin{array}{l}\text { Indoor } \\
\text { handle }\end{array}$ & Total \\
\hline Citrobacter freundii & $1(0.6)$ & $1(0.6)$ & $3(1.8)$ & $3(1.8)$ & $8(4.7)$ \\
\hline Citrobacter sp. & $1(0.6)$ & $2(1.2)$ & $0(0.0)$ & $0(0.0)$ & $3(1.8)$ \\
\hline Enterobacter sp. & $0(0.0)$ & $2(1.2)$ & $0(0.0)$ & $0(0.0)$ & $2(1.2)$ \\
\hline Enterococcus sp. & $1(0.6)$ & $1(0.6)$ & $1(0.6)$ & $1(0.6)$ & $4(2.4)$ \\
\hline Escherichia coli & $14(8.3)$ & $15(8.9)$ & $12(7.1)$ & $11(6.5)$ & $52(30.8)$ \\
\hline Klebsiella pneumoniae & $1(0.6)$ & $0(0.0)$ & $1(0.6)$ & $1(0.6)$ & $3(1.8)$ \\
\hline Klebsiella sp. & $0(0.0)$ & $2(1.2)$ & $0(0.0)$ & $1(0.6)$ & $3(1.8)$ \\
\hline Proteus mirabilis & $1(0.6)$ & $0(0.0)$ & $0(0.0)$ & $2(1.2)$ & $3(1.8)$ \\
\hline Proteus sp. & $3(1.8)$ & $3(1.8)$ & $4(2.4)$ & $3(1.8)$ & $13(7.7)$ \\
\hline Proteus vulgaris & $2(1.2)$ & $1(0.6)$ & $2(1.2)$ & $2(1.2)$ & $7(4.1)$ \\
\hline Pseudomonas sp. & $1(0.6)$ & $0(0.0)$ & $3(1.8)$ & $2(1.2)$ & $6(3.6)$ \\
\hline Salmonella enterica & $0(0.0)$ & $1(0.6)$ & $0(0.0)$ & $0(0.0)$ & $1(0.6)$ \\
\hline Salmonella sp. & $1(0.6)$ & $0(0.0)$ & $0(0.0)$ & $1(0.6)$ & $2(1.2)$ \\
\hline Staphylococcus aureus & $15(8.9)$ & $15(8.9)$ & $14(8.3)$ & $12(7.1)$ & $56(33.1)$ \\
\hline Staphylococcus epidermidis & $2(1.2)$ & $1(0.6)$ & $1(0.6)$ & $2(1.2)$ & $6(3.6)$ \\
\hline Total & $43(25.4)$ & $44(26.0)$ & $41(24.3)$ & $41(24.3)$ & $169(100)$ \\
\hline
\end{tabular}

The probabilities of sampling from each type of fomite were equal (0.971) but the type of species isolated did not occur with equal probabilities (0.000) indicating the diversity of bacteria in terms of numbers present on the fomites.

As shown in Table 1, Staphylococcus aureus (33.1\%) and Escherichia coli (30.8\%) were the predominant species. These predominant species were independent (0.205) of the type of fomite. These were followed by Proteus sp. (7.7\%), Citrobacter freundii (4.7\%), and Proteus vulgaris (4.1\%). Pseudomonas sp. (3.6\%) and Staphylococcus e.pidermidis (3.6\%) had the same occurrence. Citrobacter sp., Klebsiella pneumonia, Klebsiella sp. and Proteus mirabilis each had the same occurrence (1.8\%). Enterobacter sp. and Salmonella sp. also had the same occurrence (1.2\%). Salmonella enterica had the lowest occurrence $(0.6 \%)$.

A greater diversity of bacteria species were found on flush levers (26\%) than on toilet seats (25.4\%). This also was more than the diversity of bacteria found on tap handles $(24.3 \%)$ and indoor handles $(24.3 \%)$ which were equal.

Citrobacter freundii, Enterococcus sp., Escherichia coli, Proteus sp., Proteus vulgaris, Staphylococcus aureus and Staphylococcus epidermidis were isolated from swabs taken from all fomites. Klebsiella pneumoniae and Pseudomonas sp. were isolated from toilet seats, flush handle and indoor handle swabs only. Citrobacter $s p$. were isolated from toilet seats and flush lever swabs only. Klebsiella species were isolated from flush lever and indoor handle swabs only. Proteus 
mirabilis and Salmonella sp. were isolated from toilet seat and indoor handle swabs only. Enterobacter $s p$. were isolated from flush lever swabs only.

\subsection{Co-occurrence and Distribution of Species}

The co-occurrence of species and distribution on the washroom fomites are presented in Table 2.

Table 2: Co-occurrence and Distribution of Species

The co-occurrence and frequency distribution of bacteria species on washroom fomites $(n=68)$.

\begin{tabular}{llllll}
\hline Co-occurrence & \multicolumn{5}{c}{ Fomite n (\%) } \\
\cline { 3 - 6 } & Toilet seat & Flush lever & Tap handle & Indoor handle & Total \\
\cline { 4 - 6 } Five species & $1(1.5)$ & $0(0)$ & $0(0)$ & $0(0)$ & $1(1.5)$ \\
Four species & $1(1.5)$ & $0(0)$ & $3(4.4)$ & $0(0)$ & $4(4.4)$ \\
Three species & $7(43.8)$ & $9(13.2)$ & $6(8.8)$ & $6(8.8)$ & $28(41.2)$ \\
Two species & $6(8.8)$ & $8(11.8)$ & $4(5.9)$ & $11(16.2)$ & $29(42.6)$ \\
One species & $1(1.5)$ & $2(2.9)$ & $3(4.4)$ & $0(0)$ & $6(8.8)$ \\
Total & $\mathbf{1 6}(\mathbf{2 3 . 5})$ & $\mathbf{1 9}(\mathbf{2 7 . 9})$ & $\mathbf{1 6}(\mathbf{2 3 . 5})$ & $\mathbf{1 7}(\mathbf{2 5 . 0})$ & $\mathbf{6 8}(\mathbf{1 0 0})$ \\
\hline
\end{tabular}

As shown in Table 2, co-occurrence of bacteria species on the fomites ranged from 1-5 for toilet seats, 1-3 for flush levers, 1-4 for tap handles and 2-3 for indoor handles. The highest cooccurrence of five species was for 1 toilet seat representing $1.5 \%$ of the fomites. Single species occurred on 1 toilet seat, 2 flush levers and 3 tap handles representing a total of $8.8 \%$ of the fomites. Most of the fomites (42.6\%) had a co-occurrence of two followed by three $(41.2 \%)$.

\subsection{Antimicrobial Susceptibility of Gram Positive Isolates}

Antimicrobial susceptibility of Gram positives $(n=22)$ from selected washroom fomites.

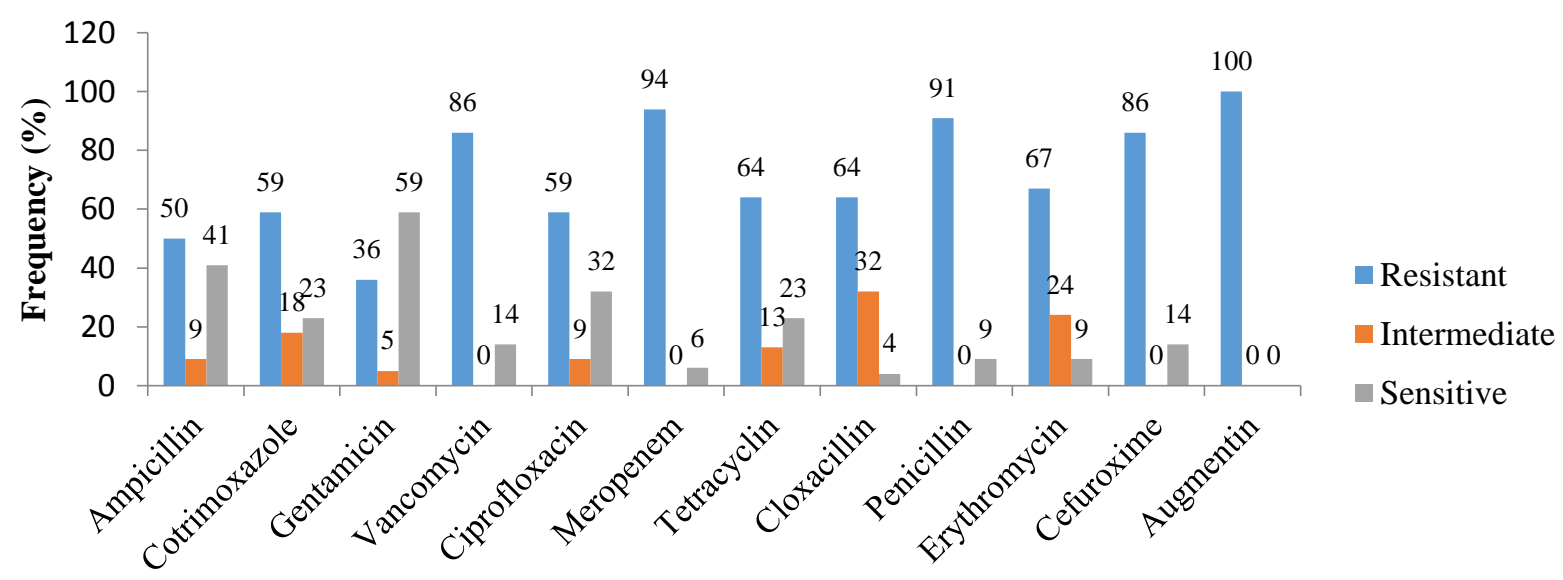

Antibiotics

Figure 2: Antimicrobial Susceptibility of Gram Positive Isolates 
For each antibiotic, the results (resistant, intermediate or sensitive) of the Gram positive bacteria antimicrobial susceptibility test did not occur with equal probability $(0.000)$ indicating the skewness of each species towards a particular susceptibility response for the tested antibiotics.

As shown in Figure 2, for the isolated Gram positive bacteria there was a high occurrence of resistance to augmentin (100\%), meropenem (94\%), penicillin (91\%), cefuroxime (86\%), vancomycin (86\%), erythromycin $(64 \%)$, tetracyclin $(64 \%)$, cloxacillin $(64 \%)$, cotrimoxazole (59\%), ciprofloxacin (59\%) and ampicillin (50\%). Resistance to gentamicin (36\%) was relatively low.

\subsection{Antimicrobial Susceptibility of Gram Negative Isolates}

Antimicrobial susceptibility of Gram negative isolates $(n=41)$ from selected washroom fomites.

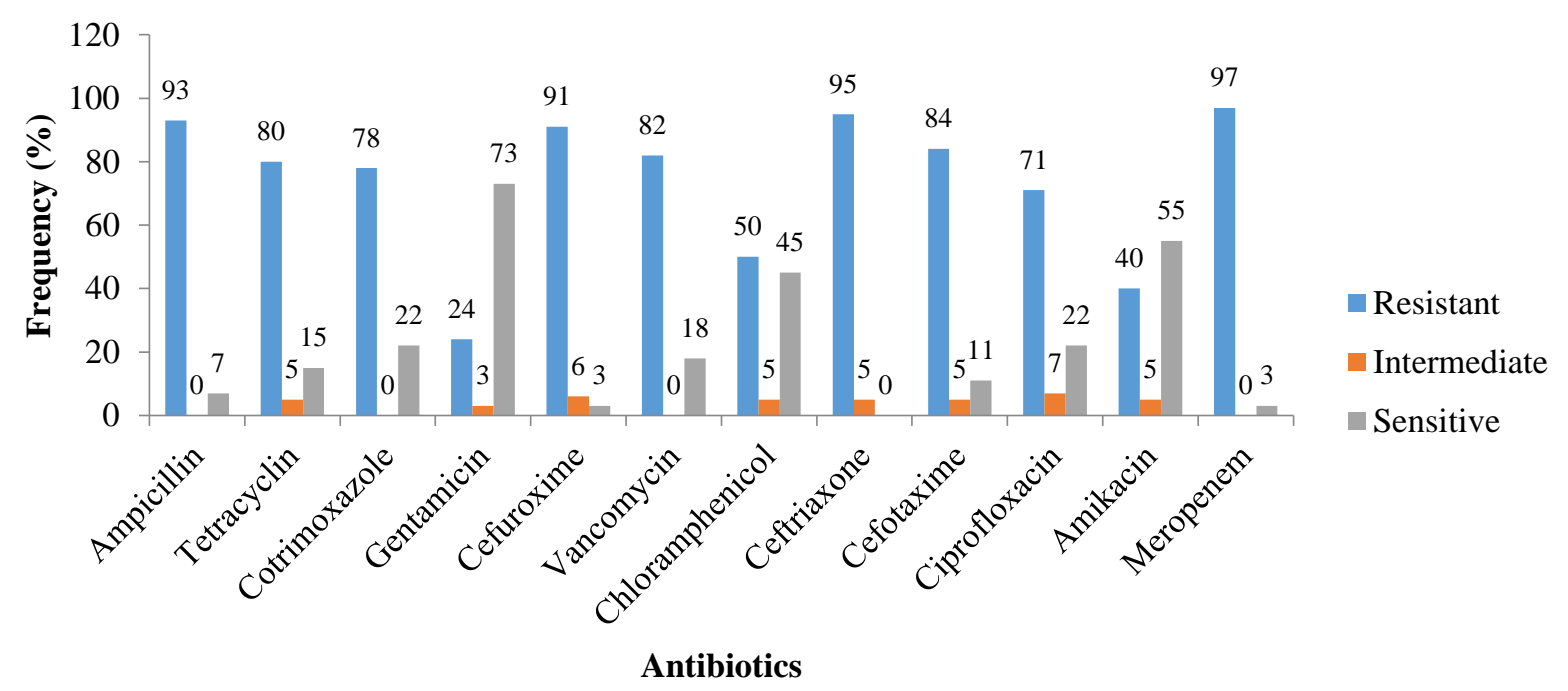

\section{Figure 2: Antimicrobial Susceptibility of Gram Negative Isolates}

For each antibiotic, the results (resistant, intermediate or sensitive) of the Gram negative bacteria antimicrobial susceptibility test did not occur with equal probability $(>0.05)$ indicating the skewness of each species towards a particular susceptibility response for the tested antibiotics.

As shown in Figure 3, for the Gram negative bacteria isolated there was a high occurrence of resistance to meropenem (97\%), ceftriaxone (95\%), ampicillin (93\%), cefotaxime (94\%), cefuroxime $(91 \%)$, vancomycin $(82 \%)$, tetracyclin $(81 \%)$, cotrimoxazole $(78 \%)$, ciprofloxacin (71\%) and Chloramphenicol (50\%). The occurrence of isolates that were resistant to amikacin (40\%) and gentamicin $(24.4 \%)$ were relatively low.

\subsection{DISCUSSION}

The diversity of bacteria on the washroom fomites comprised of not less than 15 different humanrelated species, all of which are clinically significant except Staphylococcus epidermidis which 
exist as a nonpathogenic normal human skin flora. The bacteria also comprise of serious human pathogens like Salmonella sp. and Salmonella enterica. The diversity of bacteria species were widely distributed across the different types of fomites in the washrooms.

The sanitation audit reveals the poor conditions of most of the washrooms on the university campus as well as lack of measures in place to reduce contamination and possible spread of infections. This may be due to inadequate washroom facilities to cater for the over 15,000 student population which puts a lot of pressure on the existing washrooms. McGinnis et al. (2018) reports that approximately $10 \%$ of the global disease burden is linked to inadequate water, sanitation and hygiene. The unavailability of toiletries and water in washrooms may lead to outbreaks of diarrheal diseases in the user population.

Toilet seats, flush levers, tap handles and indoor handles are surfaces which normally come into contact with contaminated hands and contaminated body parts when washrooms are used. These are nonporous surfaces. Non porous surfaces have the highest bacteria transfer rate (Lopez, 2013). The design of the washrooms is such that users cannot avoid having physical contact through handling in order to use the facility. Infection Control Today (ICT) in 2006 reported from a systematic review of literature by researchers that an incidence of hand contact with a contaminated fomite can result in different degrees of transfer of pathogens, especially Escherichia coli, Salmonella sp. and Staphylococcus aureus. An appropriate washroom design should provide minimum handling and reduce physical contact with surfaces as much as possible. This can be achieved through the use of swing doors, levers for tap handles and flush button water closets to reduce contact.

Bacteria isolated in this study reflect the diversity of species carried by the population of users of the washroom. Generally these are a threat to the health of the immunocompromised and immunosuppressed users. Similar enteric and skin flora such as Staphylococcus aureus (42.9\%), Salmonella typhimurium (21.4\%), Escherichia coli (14.3\%), Pseudomonas aeruginosa (9.5\%), Proteus mirablis (4.8\%) Klebsiella oxytoca (4.8\%) and Klebsiella pneumoniae (2.3\%) were found in a study by Alonge, Auwal, \& Aboh, 2019. The presence of the enteric bacteria on the fomites indicate possible faecal contamination. These are associated with human infections and diarrhoeal diseases, especially Salmonella enterica and other Salmonella sp. These are etiologic agents of diarrhea and can cause an outbreak among the student population. Staphylococcus aureus on the other hand are agents associated with serious diseases, especially methicillin-resistant Staphylococcus aureus. The predominance of Staphylococcus aureus may be because these being Gram positive bacteria can persist for months on dry surfaces and survive under lower humidity conditions (ICT, 2006).

Most washroom fomites (83.8\%) per the results are likely to harbor 2 to 3 bacteria contaminants. The highest co-occurrence, five species, was on a toilet seat because there is greater contact per unit area between the fomite and the skin as well as greater proximity between faecal matter and the fomite even without handling. This makes the toilet seat a high risk fomite as such users should spread tissue on the seat before sitting to reduce the probability of transmission. The flush handles were the most frequently contaminated by different diversities of bacteria because this is the first point of contact with contaminated hands after using the water closet. Also levers require proper 
handling for flushing after the water closet has been used thus contamination can easily occur through unwashed hands. This should encourage the use of water closets with flush buttons rather than levers.

A significant diversity of Gram negative bacteria showed resistance to many of the antibiotics considered for treatment including the cephalosporins (70-92\%). Diseases caused by infections with these may prove difficult in terms of treatment (Shanks \& Peteroy-Kelly, 2009). This is clearly a potential time bomb. WHO, 2017 data on mean antibiotic resistance rankings state figures between $50-82 \%$ for $3^{\text {rd }}$ generation cephalosporin-resistant enterobacteriaceae which is less than what was found in this study. This reflects the potential burden of antibiotic resistance among users of the washroom.

The Gram positive bacteria were also resistant to many of the antibiotics considered for treatment. This is a potential addition to the burden of antibiotic resistance. WHO, 2017 data on mean antibiotic resistance rankings state $22.1 \%$ for vancomycin resistant Staphylococcus aureus. In this study 86\% were resistant, indicating a possible increase in cost of treatment and period of morbidity in the event of an associated disease.

\section{CONCLUSION}

A high diversity of bacteria were found on the washroom fomites which lacked basic toiletries and were categorized as generally unclean. Most of these were clinically significant antibiotic resistant bacteria representing enteric and skin flora of the users. Bacteria were present on all the sampled fomites with co-occurrence ranging from one to five. The occurrence of antibiotic resistant bacteria was high.

\section{RECOMMENDATION}

As part of infection control measures, to prevent indirect transmission through washroom fomites basic toiletries should be made available in washroom facilities. Designs of doors, taps and levers in washrooms should be of the kind that require minimum contact from users. Users must also practice personal hygiene and also carry hand-sanitizers to disinfect their hands after using the washrooms. There should also be proper regular cleaning of the washrooms with effective concentrations of disinfectant and decontamination solutions. The concentration of the disinfectant and decontamination solutions used by the genitors to clean the washrooms should be evaluated to ascertain its efficacy against bacterial contaminants.

\section{References}

Alonge, O.O., Auwal, B.M., Aboh, M.I. (2019). Bacterial contamination of toilet door handles on Baze University Campus Abuja Nigeria. African Journal of Clinical and Experimental Microbiology. doi: 10.4314/ajcem.v20i1.5

Infection Control Today. (2006). Fomites and infection transmission. Retrieved April 3, 2020 from https://www.infectioncontroltoday.com/hand-hygiene/fomites-and-infection-transmission

Margas, E., Maguire, E., Berlan, C.R., Welander, F. (2013). Assessment of the environmental microbiological cross contamination following hand drying with paper hand towels or an air blade dryer. Journal of Applied Microbiology, 115,572-582. doi:10.1111/jam.12248 
McGinnis, S., Marini, D., Amatya, P., Murphy, H. M. (2019). Bacterial contamination on atrine surfaces in community and household latrines in Kathmandu, Nepal. International Journal of Environmental Research and Public Health, 16, 257. doi:10.3390/ijerph16020257

Ogba, O. M, \& Obio, O. M. (2018). Microbial spectrum on public toilet seats. Annals of Microbiology and Infectious Diseases, 1, 58-62. Retrieved from https://www.sryahwapublications.com/annals-of-microbiology-and-infectiousdiseases/volume-1-issue-1/9.php

Julian, T.R. (2011). Fomites in infectious disease transmission: a modeling, laboratory, and field study on microbial transfer between skin and surfaces (Unpublished). Retrieved from http://purl.stanford.edu/cf347cn1097

Shanks, C. R. \& Peteroy-Kelly, A. (2009). Analysis of antimicrobial resistance in bacteria found at various sites on surfaces in an urban university. Bios, 80, 105-113. Retrieved from https://doi.org/10.1893/011.080.0301

Suen, L.K.P., Siu, G.K.H., Guo, Y.P., Yeung S.K.W., Lo, K.Y.K., O’Donoghue, M. (2019). The public washroom - friend or foe? An observational study of washroom. Antimicrobial Resistance and Infection Control, 48,1-6. doi: 10.1186/s13756-019-0500-z

World Health Organization (2017). Prioritization of pathogens to guide discrepancy, research and development of new antibiotics for drug-resistant bacterial infections, including tuberculosis. Retrieved from https://www.who.int/medicines/areas/rational_use/prioritization-of-pathogens/en/ 